\title{
Pharmacological Evidence for a Motivational Role of $\kappa$-Opioid Systems in Ethanol Dependence
}

\author{
Brendan M Walker*,' and George F Koob' \\ 'Committee on the Neurobiology of Addictive Disorders, The Scripps Research Institute, La Jolla, CA, USA
}

\begin{abstract}
The purpose of this study was to test the hypothesis that activation of the dynorphin/kappa ( $\kappa$ )-opioid system has a role in the increased consumption of ethanol in dependent animals. The effects of three opioid receptor antagonists with different effects on opioid receptors, naltrexone, nalmefene, and nor-binaltorphimine (nor-BNI), were compared in their ability to decrease ethanol self-administration in nondependent and ethanol-dependent male Wistar rats. Nalmefene and naltrexone are both opioid receptor ligands with comparable molecular weights and pharmacokinetic profiles, but differing specificity for the three opioid receptor subtypes at low doses, while nor$\mathrm{BNI}$ is a selective $\kappa$-opioid receptor antagonist. Dependence was induced in half the animals by subjecting them to a 4-week intermittent vapor exposure period in which animals were exposed to ethanol vapor for $14 \mathrm{~h}$ per day. Subsequent to dependence induction, nalmefene, naltrexone, and nor-BNI were tested for their ability to modulate self-administration of ethanol in vapor-exposed and control rats. The results indicated that both nalmefene and naltrexone induced a significant dose-dependent decrease in the number of lever presses for ethanol in both groups of animals. However, in ethanol-dependent animals, nalmefene was significantly more effective in suppressing ethanol intake than naltrexone. Nor-BNI selectively attenuated ethanol-dependent self-administration while leaving nondependent ethanol self-administration intact. Because naltrexone is primarily selective for the $\mu$-opioid receptor, and nalmefene is primarily selective for the $\mu$ - and $\kappa$-opioid receptor subtypes, the fact that nalmefene demonstrates more suppression in dependent animals suggests that opioid systems distinct from the $\mu$-regulated portion may be involved in the increased drinking seen during withdrawal in dependent animals. The results with nor-BNI confirm that $\kappa$-opioid receptor antagonism selectively decreases dependence-induced ethanol self-administration, which supports the hypothesis that dynorphin/ $\kappa$-opioid systems are dysregulated in dependence and contribute to the increased drinking seen during acute withdrawal in dependent rats.

Neuropsychopharmacology (2008) 33, 643-652; doi:I 0. I038/sj.npp. I 301438; published online 2 May 2007
\end{abstract}

Keywords: alcoholism; alcohol self-administration; reinforcement; dependence; opioids; dynorphin

\section{INTRODUCTION}

The acute effects of ethanol have been shown to be both reinforcing and rewarding in animal models such as operant self-administration (Anderson and Thompson, 1974; Smith and Davis, 1974) and the conditioned place preference paradigm (Bozarth, 1990; Walker and Ettenberg, 2007). Ethanol produces its effects on the central nervous system via a variety of pharmacological mechanisms. These include alterations in the function of the cholinergic, dopaminergic, $\gamma$-aminobutyric acid, glutamatergic, opioidergic, and serotonergic neurotransmitter systems (for review see Eckardt et al, 1998). In the case of the endogenous opioid system and its receptor subtypes $(\mu, \delta$, $\kappa$ - selective for the three main classes of endogenous

\footnotetext{
*Correspondence: Dr BM Walker, Committee on the Neurobiology of Addictive Disorders, The Scripps Research Institute, 10550 N. Torrey Pines Rd, SP30-I50I, La Jolla, CA 92037, USA, Tel: + 858784 7240, Fax: + 858784 7475, E-mail: bwalker@scripps.edu

Received 28 November 2006; revised 21 March 2007; accepted 30 March 2007
}

opioids: $\beta$-endorphin, enkephalins, and dynorphins, respectively), acute ethanol has been shown to stimulate the release of $\beta$-endorphin, enkephalins, and dynorphin in humans and rats (Gianoulakis et al, 1996; Marinelli et al, 2003, 2004; Dai et al, 2005; Marinelli et al, 2005, 2006). Blockade of the receptors for these endogenous ligands by naltrexone and naloxone has been shown to reliably decrease ethanol consummatory behaviors (Gonzales and Weiss, 1998; Stromberg et al, 2001; Coonfield et al, 2002; Shoemaker et al, 2002). In fact, evidence has led researchers to postulate that a surfeit of opioidergic activity enhances the rewarding properties of ethanol (Hubbell et al, 1988; Marglin et al, 1988; Reid, 1996) and may be related to continuing ethanol intake once it has begun (ie binge drinking). Furthermore, $\beta$-endorphins and enkephalins have themselves been shown to be rewarding (ie produce a positive hedonic state) and reinforcing in that they produce place preferences (Amalric et al, 1987; Agmo and Gomez, 1991) and support self-administration behavior (Belluzzi and Stein, 1977; Goeders et al, 1984).

In contrast, $\kappa$-opioid receptor agonists produce place aversions (Mucha and Herz, 1985) and are morphologically 
in a spatial location that enables them to oppose the effects of $\mu$-opioid receptor agonists (Di Chiara and Imperato, 1988 b) and directly inhibit motivationally relevant dopamine neurons at both the somatic and terminal regions within the mesocorticolimbic dopamine system (Di Chiara and Imperato, 1988a; Margolis et al, 2003, 2006).

An important question is how opioidergic systems change with the development of dependence when there is an increase in the motivation to consume ethanol. Aside from the ability of acute ethanol to activate endogenous opioids, numerous investigations have evaluated the effects of chronic ethanol on opioid peptide systems. In both humans and animals, chronic ethanol exposure has induced changes in opioid peptide systems that generally reflect downregulation of the positive and upregulation of the negative hedonic portion of the systems. These changes range from alterations in the levels of the peptides themselves (Gianoulakis et al, 1996; Lindholm et al, 2000), changes in receptor densities and effector systems (Turchan et al, 1999; Chen and Lawrence, 2000), as well as modifications of mRNA coding for both the peptides and receptors (Przewlocka et al, 1997; Rosin et al, 1999; Cowen and Lawrence, 2001). Therefore, the purpose of the present series of experiments was to test the hypothesis that alterations in $\kappa$-opioid-regulated systems have a role in mediating the increased ethanol consumption associated with dependence.

To evaluate ligands with differential affinity for the opioid receptor subtypes for their ability to attenuate ethanol selfadministration, the present experiment compared the effects of three opioid receptor antagonists (ie naltrexone, nalmefene, and nor-binaltorphimine (nor-BNI)) on nondependent and ethanol-dependent self-administration of ethanol during acute withdrawal. Naltrexone is now an approved drug for the treatment of alcoholism based on its efficacy in reducing craving for and consumption of ethanol (Volpicelli et al, 1992), and nalmefene has shown clinical utility in the treatment of alcoholism (Mason et al, 1994; Anton et al, 2004). However, naltrexone, although classified as a general opioid receptor antagonist, actually has a higher affinity for the $\mu$-opioid receptor subtype than the $\delta$ and $\kappa$ subtypes at low doses (Abbott et al, 1986; Millan, 1989; Millan et al, 1989; Walker et al, 1994; Stromberg et al, 1998). Nalmefene is also classified as a general opioid receptor antagonist and is equipotent with naltrexone at the $\mu$-opioid receptor, but unlike naltrexone, has a higher affinity for the $\kappa$ and $\delta$ receptors in rats (Michel et al, 1985) and the $\kappa$ receptor in humans (Bart et al, 2005). Therefore, even at low doses, nalmefene can be considered a 'true' general opioid receptor antagonist.

Thus, based on the fact that naltrexone and nalmefene have dissociable binding profiles at the opioid receptors, and that previous research has shown acute changes in $\beta$ endorphin, met-enkephalin, and dynorphin in response to ethanol (Gianoulakis et al, 1996; Marinelli et al, 2003, 2004, 2005, 2006; Dai et al, 2005), the purpose of the present study was to compare ligands with mechanisms of action that are either $\mu$-opioid (ie naltrexone) or $\mu$-, $\delta$-, and $\kappa$-opioid (ie nalmefene) receptor based for their ability to attenuate ethanol self-administration in nondependent and ethanoldependent rats during acute withdrawal. Furthermore, to test directly the contribution of dynorphin systems to the increased ethanol self-administration observed during acute withdrawal, central $\kappa$-opioid receptors were selectively targeted for antagonism in nondependent and ethanoldependent rats. Therefore, in one experiment, nalmefene and naltrexone were peripherally administered, and in the second, the selective $\kappa$-opioid receptor antagonist nor-BNI was administered intracerebroventricularly (ICV) immediately before operant ethanol self-administration sessions in nondependent rats and ethanol vapor-exposed rats during acute withdrawal.

\section{METHODS}

\section{Animals}

Twenty-eight male Wistar rats (Charles River Laboratory, Kingston, NY) weighing approximately $200 \mathrm{~g}$ upon arrival were communally housed ( $2-3$ per cage) with food and water available ad libitum. The animals were housed within a temperature-controlled $\left(21.5^{\circ} \mathrm{C}\right)$ vivarium that was maintained on a $12 \mathrm{~h}$ light/dark cycle (lights on at 0800 ). On their arrival in the vivarium, animals were gently handled daily over a 1-week period (until the onset of operant conditioning). The work described herein adheres to the guidelines stipulated in the NIH Guide for the Care and Use of Laboratory Animals and was reviewed and approved by The Scripps Research Institute's Institutional Animal Care and Use Committee.

\section{Operant Chambers}

The operant chambers (Coulbourn Instruments, Allentown, PA) utilized in the present study had two retractable levers located $4 \mathrm{~cm}$ above a grid floor and $4.5 \mathrm{~cm}$ to each side of a two-well acrylic drinking cup that allowed for up to two solutions to be administered upon the pressing of the appropriate lever. Recording of operant responses and subsequent fluid delivery were controlled by custom software running on a PC computer. A lever press resulted in the activation of a 15 r.p.m. Razel syringe pump (Stanford, CT) which delivered $0.1 \mathrm{ml}$ of fluid to the appropriate well over $0.5 \mathrm{~s}$. During the $0.5 \mathrm{~s}$ of pump activation, no responses were recorded. Operant chambers were individually housed in ventilated, sound-attenuated cubicles to minimize environmental disturbances.

\section{Acquisition of Operant Ethanol Self-Administration}

The initial operant training was based on an adaptation of Samson's sweetened fading procedure (Samson, 1986) and allowed animals to initially respond for a 'SuperSacc' solution (SS) consisting of $3 \%$ glucose and $0.125 \%$ saccharin. This solution serves as a potent reinforcer and makes it unnecessary to water restrict animals to induce the initial lever pressing behavior. For 1 week, animals were trained to press on a continuous schedule of reinforcement (fixed-ratio 1) for SS alone. The animals were then switched to a two-lever condition with $\mathrm{SS}+10 \%$ ethanol $(\mathrm{w} / \mathrm{v} ; 10 \mathrm{E})$ resulting from an operant response on one of the levers and water resulting from a response on the alternate lever, with the position of the SS $+10 \mathrm{E}$ lever and water lever being alternated from left to right each session. After 1 week of SS 
$+10 \mathrm{E}$, animals were allowed to self-administer a $0.125 \%$ saccharin $+10 \mathrm{E}$ solution for four sessions at which point the animals were switched to a $10 \mathrm{E}$ solution. Animals were allowed to self-administer $10 \mathrm{E}$ and water until stable selfadministration rates were established before the onset of intermittent ethanol vapor exposure. A total of 16 animals were allocated for the naltrexone/nalmefene dose-response curve experiment, while 12 animals were designated for use in the nor-BNI experiment. Once stable ethanol selfadministration had occurred, the animals designated for each experiment were split into two groups that were matched for their ethanol self-administration over 26 (ie nalmefene/naltrexone experiment, $n=8$ per group) or 23 (ie nor-BNI experiment, $n=6$ per group) sessions, with one group designated as 'ethanol vapor exposed' and the other as 'air exposed'.

\section{Surgical Procedures}

Following stable ethanol self-administration, those animals used in the nor-BNI experiment were implanted with bilateral guide cannulae into the lateral ventricles. Surgeries were conducted under deep gas anesthesia produced by inhalation of $2 \%$ isofluorane gas (Savmart Pharmaceutical Services Inc., San Diego, CA). Bilateral stainless steel guide cannulae (24 gauge; Plastics One, Roanoke, VA) were implanted using standard stereotaxic techniques and the coordinates (from dura) of $\mathrm{AP}-0.36, \mathrm{DV}-4.4$ and $\mathrm{ML} \pm 3.7$ at $-20^{\circ}$ from verticle (Paxinos and Watson, 2005). The guide cannulae were secured in place by the use of acrylic dental cement and stainless steel jeweler's screws that were affixed to the animal's skull and served as anchor points. The open ends of the guide cannulae were sealed by inserting obdurators (31 gauge; Plastics One, Roanoke, VA); this served to maintain cannula patency and reduce the risk of infection. Following surgery, the animals were allowed to recover for 1 week before being placed into the vapor chambers for dependence induction.

\section{Ethanol Vapor Chamber Process}

Ethanol vapor exposure has been shown to reliably allow for the titration of blood alcohol levels (BALs) that are sufficient for inducing ethanol dependence (Roberts et al, 1996, 2000; O’Dell et al, 2004). In this paradigm, BALs can be easily titrated by the experimenter to fit established criterion and the animals show normal weight gain and are freely moving (Rogers et al, 1979). Standard rat cages were housed in separate clear plastic chambers that were sealed and ethanol vapor or air was pumped through the chambers. Ethanol vapor was created by dripping $95 \%$ ethanol into $2000 \mathrm{ml}$ Erlenmeyer flasks that remained at $50^{\circ} \mathrm{C}$ due to a warming tray. Air $(11 \mathrm{l} / \mathrm{min})$ was passed over the bottom of the flask so that when the ethanol contacted the warm glass and was vaporized, the air carried it into the vapor chamber. Alteration of the ethanol vapor concentration was accomplished by modulating the airflow into the chamber. Target BALs were 150-200 mg\% across the 4-week exposure period and were determined by sampling blood collected from the tail $(0.5 \mathrm{ml})$ twice a week and assaying it for ethanol content using the Analox microstat GM7 (Analox Instruments Ltd., Lunenberg, MA).
In these experiments, animals were subjected to intermittent vapor exposure ( $14 \mathrm{~h}$ on/10 h off) over the course of 4 weeks. Intermittent vapor exposure has been shown to be more effective at inducing dependence (ie enhanced ethanol self-administration) compared to continuous ethanol vapor exposure (O’Dell et al, 2004).

\section{Post-Vapor Pharmacological Challenge of Ethanol Self-Administration Responding}

Following the 4-week dependence induction period resulting from ethanol vapor exposure, all animals were tested in self-administration sessions on Tuesdays and Fridays at a time point corresponding to $6 \mathrm{~h}$ into withdrawal for the ethanol vapor-exposed animals (ie $6 \mathrm{~h}$ after the ethanol vapor was terminated for that day) to confirm differences in baseline ethanol self-administration responding between the ethanol vapor- and air-exposed groups and to allow for stable ethanol self-administration behavior. Following each test session, the animals were returned to the vapor chambers and allowed to reexperience ethanol vapor or air as described above.

\section{Nalmefene/Naltrexone Pharmacological Challenges}

When ethanol self-administration was stable for 3 days, a s.c. saline injection was given $30 \mathrm{~min}$ before the next self-administration session to determine whether such an injection would affect baseline self-administration. Once it was deemed ineffective at altering baseline self-administration, pharmacological challenges ensued. Initially, a nalmefene dose-response curve $(0.0,0.025,0.05$, and $0.1 \mathrm{mg} / \mathrm{kg}$, s.c.) was conducted according to a Latin square-design with test days being carried out on Tuesdays and Fridays to minimize drug carryover effects. On all test days, blood was collected before the ethanol vapor termination for the test day to confirm that target BALs were met. Following the test trials, the animals were returned to the vapor chambers.

Once the nalmefene dose-response curve for ethanoldependent and -nondependent animals was completed, the animals were allowed to reestablish baseline ethanol selfadministration over three sessions (over 1 week) that was comparable to their pre-nalmefene dose-response curve performance. Subsequently, a naltrexone dose-response curve $(0.0,0.1,0.5$, and $1 \mathrm{mg} / \mathrm{kg}$, s.c.) was conducted according to a Latin square design with test days being carried out on Tuesdays and Fridays at a time point corresponding to $6 \mathrm{~h}$ of ethanol withdrawal.

\section{Nor-Binaltorphimine Pharmacological Challenge}

After 2 days of post-dependence induction ethanol selfadministration sessions, an ICV vehicle infusion was injected immediately before the next self-administration session. After habituation to the injection procedure, pharmacological challenges ensued. Nor-BNI $(0.5,1$, and $2 \mu \mathrm{g} /$ side) was administered immediately before ethanol self-administration sessions according to a Latin square design. On all test days, blood was collected before the ethanol vapor termination for the test day to confirm that 
target BALs were met. Following the test trials, the animals were returned to the vapor chambers.

\section{Drugs}

Naltrexone was purchased from Sigma Chemical Co. (St Louis, MO), and nalmefene was donated by Mallinckrodt Inc. (Hazelwood, MO). Both compounds were soluble in $0.9 \%$ physiological saline and were injected via a SC route of administration $30 \mathrm{~min}$ before the operant ethanol selfadministration sessions.

Nor-binaltorphimine was purchased from Tocris Bioscience (Ellisville, MO). Nor-BNI was soluble in $0.9 \%$ physiological saline and was injected via an ICV route of administration immediately before the operant ethanol selfadministration sessions. Nor-BNI was administered into the lateral ventricles in a volume of $0.5 \mu \mathrm{l} /$ side over $90 \mathrm{~s}$, using a syringe pump fitted with a $10 \mu \mathrm{l}$ syringe. Internal cannulae (31 gauge, extending $2 \mathrm{~mm}$ beyond cannula guide; Plastics One, Roanoke, VA) were left in place for $60 \mathrm{~s}$ following the termination of the infusion to ensure drug diffusion away from the cannula tip.

\section{Data Analysis}

To confirm statistically appropriate dependent-like acute withdrawal behavior, responding on the last three postvapor ethanol self-administration sessions before the pharmacological testing were compared in ethanol vaporand air-exposed animals using a mixed-factor two-way analysis of variance (ANOVA). The between-subjects factor was level of dependence (ie vapor exposed or air exposed) and the within-subjects factor was session.

\section{Data Analysis: Nalmefene/Naltrexone}

One animal was removed from the nondependent group due to health complications. Dependent and nondependent ethanol and water self-administration data following nalmefene and naltrexone administration were first individually analyzed using a mixed factor two-way ANOVA with level of dependence (ie vapor exposure or air exposure) as the between-subjects factor and dose as the within-subjects factor. Next, nalmefene and naltrexone dose-response curves for ethanol and water responding were analyzed using a one-way ANOVA. Post hoc least significant difference (LSD) tests were conducted if a main effect for dose was found. The dose ranges for nalmefene and naltrexone were constructed so that at least one dose of each drug was overlapping (based on the molecular weights), which allowed for direct comparisons. A two-way mixed-factor ANOVA was computed on the effects of $0.1 \mathrm{mg} / \mathrm{kg}$ nalmefene and naltrexone in nondependent and ethanol-dependent animals with level of dependence as the between-groups factor and drug as the within-subjects factor. Post hoc paired-sample $t$-tests were conducted on the appropriate pairings if an interaction was found.

\section{Data Analysis: Nor-Binaltorphimine}

Due to loss of a cannula guide, one animal in the dependent group was removed from the study. Of the remaining eleven animals, three from the nondependent group and one from the ethanol-dependent group had missing values. To prevent loss of all data from those animals using a within-subjects analysis, five missing observations for ethanol and water reinforced lever pressing following norBNI administration ( $11 \%$ of the data matrix) were imputed using the Gibbs sampler algorithm for a multivariate mixed model with incomplete data, as previously described (Schafer, 1999; Schafer and Graham, 2002). Ten complete data sets were imputed, and each was analyzed with a mixed-model two-way ANOVA using PROC MIANALYZE of SAS 9.1 (SAS Institute, Cary, NC). Parameter estimates from each analysis were then combined to obtain a single set of results following procedures described elsewhere (Rubin, 1987, 1996).

\section{RESULTS}

\section{Nalmefene/Naltrexone}

The data from the last three post-vapor period selfadministration sessions before the onset of pharmacological challenges (Figure 1, right panel) was analyzed using a mixed factor two-way ANOVA which identified a main effect for vapor exposure $(\mathrm{F}(1,13)=5.173 ; p<0.05)$ indicating the induction of dependence was successful. Additionally, since the response pattern across days was stable, the ANOVA did not find significant differences for session $(\mathrm{F}(2,26)=0.049 ; p>0.05)$ or a Session $\times$ Vapor interaction $(\mathrm{F}(2,26)=0.044 ; p>0.05)$.

Figure 2 illustrates the effects of nalmefene and naltrexone on ethanol-dependent and nondependent self-administration of ethanol. The two-way ANOVA analyzing the effects of nalmefene on ethanol responding identified a main effect of Vapor $(\mathrm{F}(1,13)=11.048 ; p<0.01)$ and Dose $(\mathrm{F}(3,39)=15.686 ; p<0.001)$. The results of the repeatedmeasures one-way ANOVA computed on the effects of nalmefene on ethanol self-administration indicated a main effect of Dose in both the ethanol-dependent $(\mathrm{F}(3,24)=$ $11.086 ; p<0.001)$ and nondependent $(\mathrm{F}(3,18)=7.603$; $p<0.01)$ animals. Post hoc LSD tests confirmed that nalmefene dose-dependently reduced ethanol self-administration compared to vehicle with the $0.025(p<0.05$ for ethanol-dependent and 0.01 for nondependent), 0.05 $(p<0.01)$, and $0.1 \mathrm{mg} / \mathrm{kg} \quad(p<0.01)$ doses producing significant effects. The two-way ANOVA computed on the naltrexone data identified a main effect of Vapor $(\mathrm{F}(1,13)=4.927 ; \quad p<0.05)$, Dose $(\mathrm{F}(3,39)=26.835$; $p<0.001)$ and a Vapor $\times$ Dose interaction $(\mathrm{F}(3,39)=5.594$; $p<0.01)$. The repeated measures one-way ANOVA identified that the effects of naltrexone on ethanol self-administration in ethanol-dependent and nondependent groups showed a main effect of Dose $(\mathrm{F}(3,21)=19.482 ; p<0.001$ and $\mathrm{F}(3,18)=11.39 ; p<0.001$, respectively). Furthermore, post hoc LSD tests confirmed that compared to vehicle, the $0.1 \quad(p<0.05), \quad 0.5 \quad(p<0.01)$ and $1.0 \mathrm{mg} / \mathrm{kg} \quad(p<0.01)$ naltrexone doses significantly reduced responding in nondependent animals, whereas only the $0.5(p<0.01)$ and $1.0 \mathrm{mg} / \mathrm{kg}(p<0.01)$ doses significantly affected ethanol-dependent self-administration of ethanol. Neither nalmefene nor naltrexone affected water self-administration for ethanoldependent and -nondependent animals (see Figure 3). 


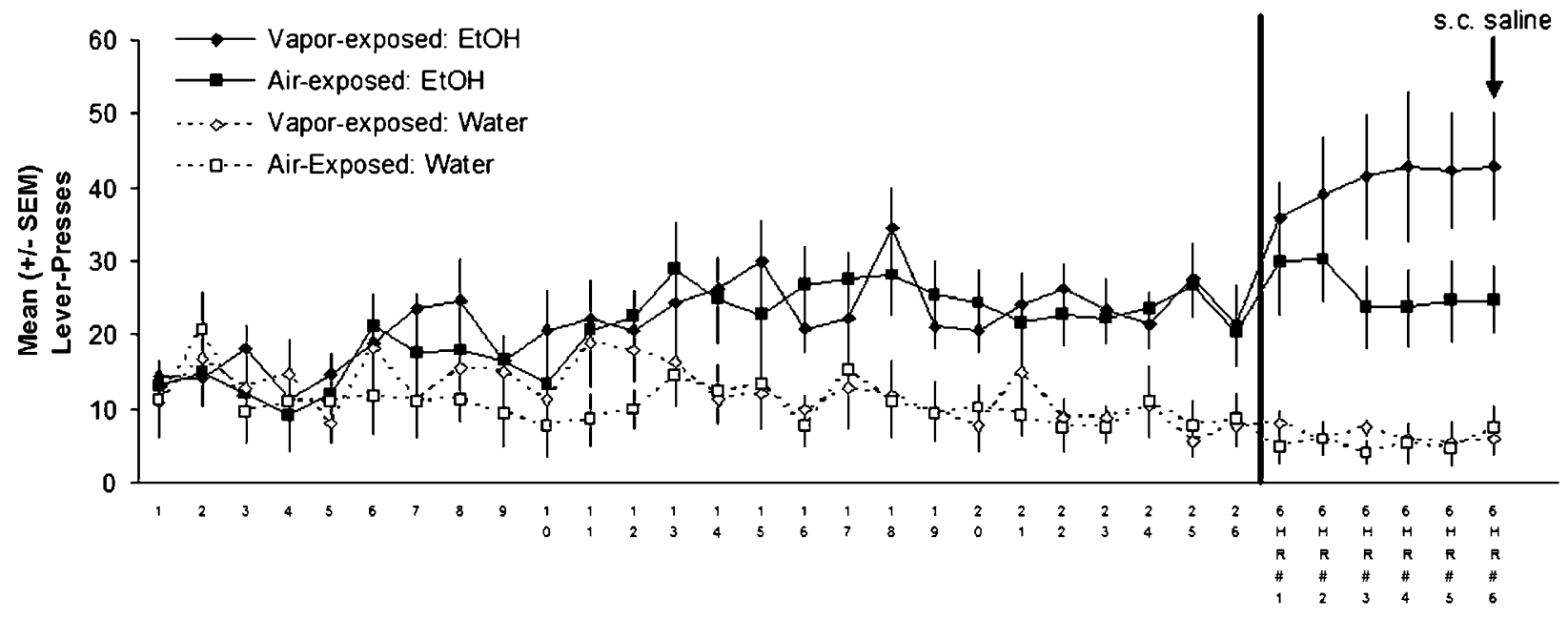

Ethanol Session

Figure I Left panel: Mean ( \pm SEM) responses for ethanol and water prior to dependence induction for the ethanol vapor-and air-exposed groups. Right panel: Mean ( \pm SEM) responses for ethanol and water at a time point corresponding to $6 \mathrm{~h}$ into withdrawal (ie, acute withdrawal) following dependence induction. The vapor-exposed animals display escalated responding compared to the air-exposed controls.
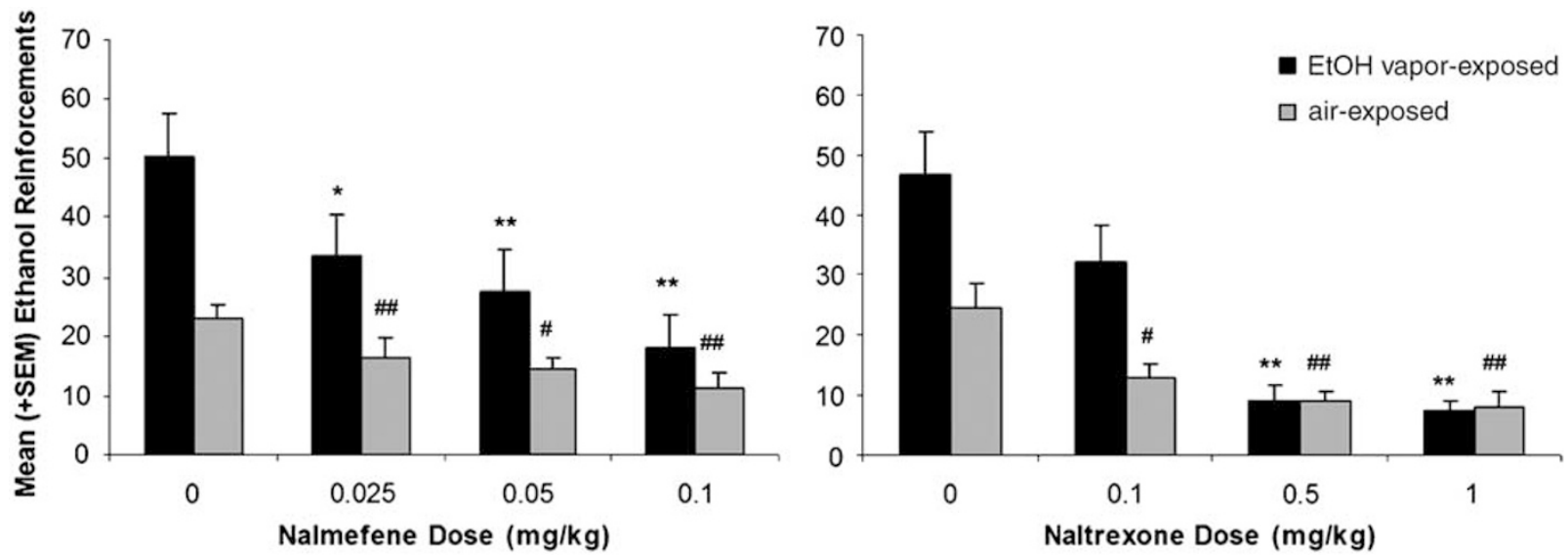

Figure 2 Mean (+SEM) responses for ethanol following nalmefene $(0.0-0.1 \mathrm{mg} / \mathrm{kg})$ and naltrexone $(0.0-1.0 \mathrm{mg} / \mathrm{kg})$ administration in nondependent and ethanol-dependent animals during acute withdrawal. Both nalmefene and naltrexone-induced dose-dependent decreases in ethanol self-administration $\left({ }^{*} p<0.05\right.$ and ${ }^{*} * p<0.0$ I compared to vapor-exposed vehicle dose; ${ }^{\#} p<0.05$, and ${ }^{\# \#} p<0.0$ I compared to air-exposed vehicle dose).
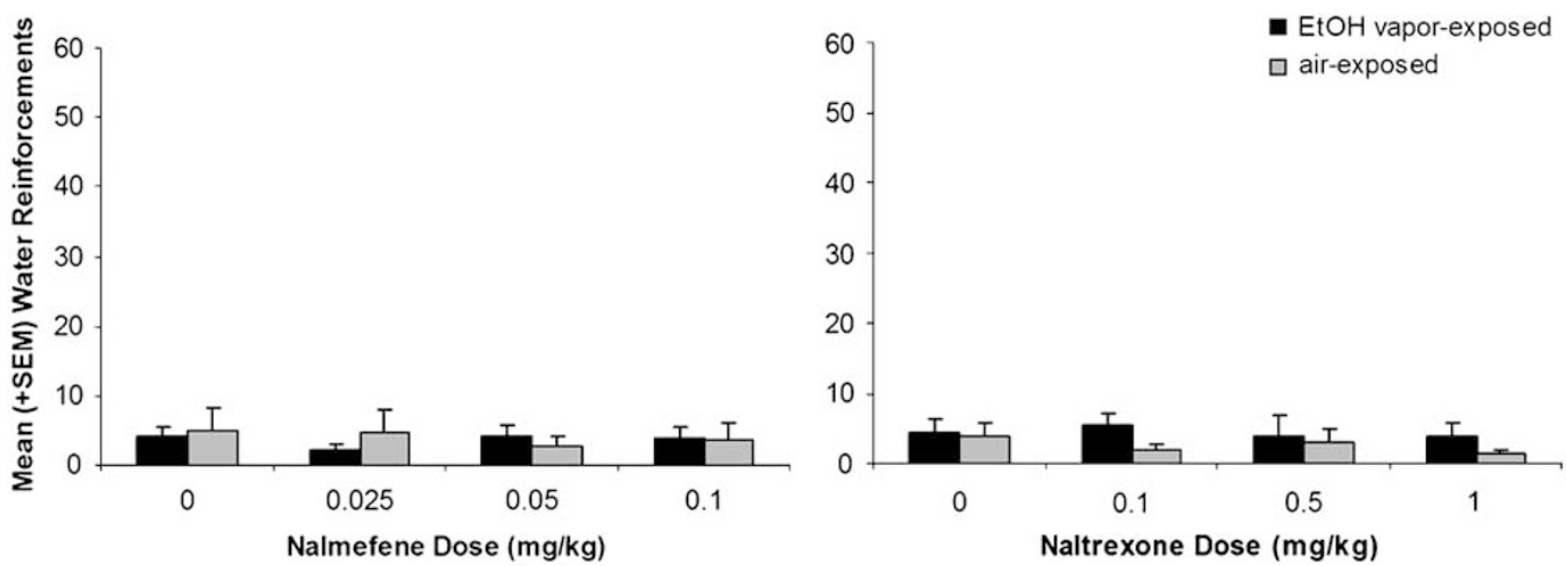

Figure 3 Mean (+SEM) responses for water following nalmefene $(0.0-0.1 \mathrm{mg} / \mathrm{kg})$ and naltrexone $(0.0-1.0 \mathrm{mg} / \mathrm{kg})$ administration in nondependent and ethanol-dependent animals during acute withdrawal. 


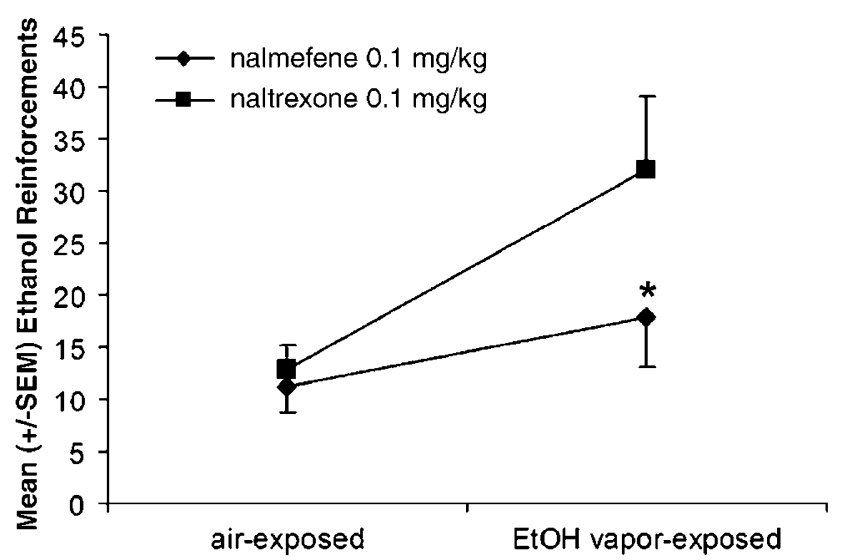

Figure 4 Mean $( \pm$ SEM) responses for ethanol in nondependent and ethanol-dependent animals following $0.1 \mathrm{mg} / \mathrm{kg}$ nalmefene or naltrexone. Nalmefene attenuated responding for ethanol significantly more than naltrexone $(* p<0.05)$ in ethanol-dependent animals.

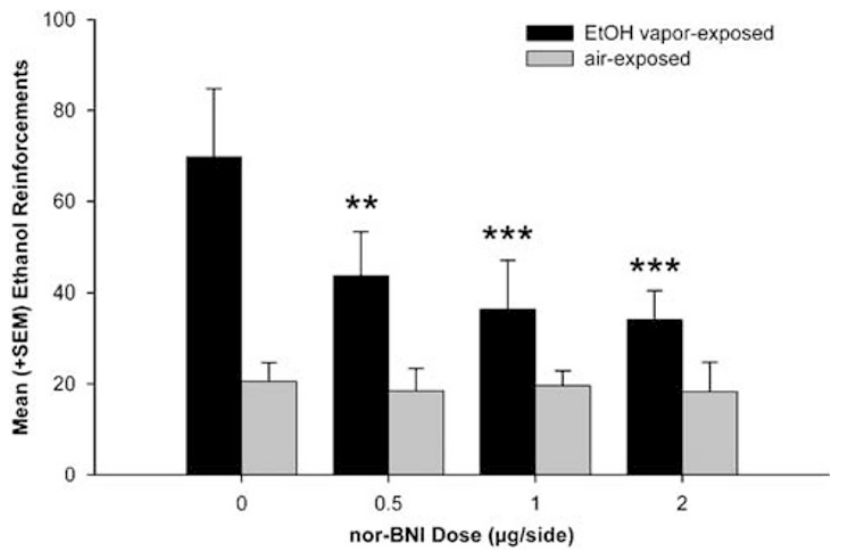

Figure 5 Mean (+SEM) responses for ethanol in nondependent and ethanol-dependent animals during acute withdrawal following nor-BNI treatment before self-administration sessions. Nor-BNI selectively attenuated ethanol self-administration in dependent animals $(* * p<0.0$ l, **** $p<0.00$ I compared to vapor-exposed vehicle dose).

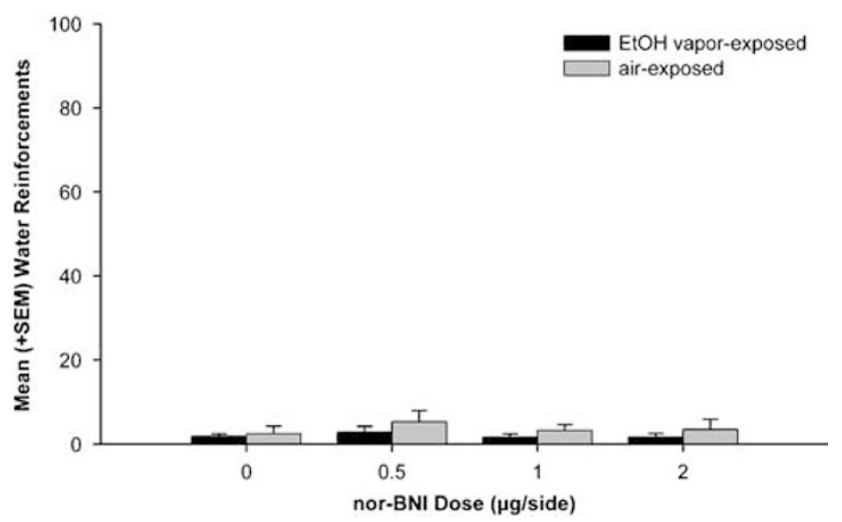

Figure 6 Mean (+SEM) responses for water in nondependent and ethanol-dependent animals during acute withdrawal following nor-BNI treatment before self-administration sessions.

Figure 4 depicts the effect of $0.1 \mathrm{mg} / \mathrm{kg}$ nalmefene and naltrexone on nondependent and ethanol-dependent selfadministration of ethanol. A mixed-factor two-way ANOVA identified a significant main effect for Vapor and Drug $(\mathrm{F}(1$, $13)=4.847 ; p<0.05$ and $\mathrm{F}(1,13)=8.444 ; p<0.05$, respectively), as well as a significant Vapor $\times$ Drug interaction $(\mathrm{F}(1,13)=5.379 ; p<0.05)$. Consequently, paired-sample $t$-tests were computed for the effects of nalmefene and naltrexone on ethanol-dependent self-administration of ethanol. The results showed that $0.1 \mathrm{mg} / \mathrm{kg}$ nalmefene was significantly $(p=0.014)$ more effective than $0.1 \mathrm{mg} / \mathrm{kg}$ naltrexone in suppressing ethanol self-administration in ethanol-dependent rats.

\section{Nor-Binaltorphimine}

The data from the three post-vapor self-administration sessions before the onset of pharmacological challenges was analyzed using a mixed factor two-way ANOVA. A main effect for level of Vapor $(\mathrm{F}(1,9)=23.655 ; p<0.001)$ was identified, which showed that the induction of dependence was successful.

The effect of nor-BNI on ethanol self-administration for nondependent and ethanol-dependent animals at a time point corresponding to $6 \mathrm{~h}$ into withdrawal is displayed in Figure 5. The parameter estimates computed from the results of the mixed-model two-way ANOVAs that were conducted on the imputed data sets for ethanol selfadministration following nor-BNI administration identified a main effect of Vapor $(\mathrm{t}(1,9)=-2.75 ; p<0.05)$, Dose $(\mathrm{t}(3,27)=-3.59 ; p>0.01)$, and a significant Vapor $\times$ Dose interaction $(\mathrm{F}(3,27)=4.12-5.77 ; p<0.01)$. Post hoc comparisons identified that responding for ethanol after infusions of the $0.5,1$, and $2 \mu \mathrm{g} /$ side doses of nor-BNI in ethanol-dependent animals was significantly reduced compared to vehicle-treated sessions $(p<0.01)$, although none of the doses statistically differed from each other. Nor-BNI failed to affect nondependent ethanol self-administration at any dose. As seen in Figure 6, neither nondependent nor ethanol-dependent water self-administration was altered by nor-BNI.

\section{DISCUSSION}

The primary purpose of this study was to compare the effects of three opioid antagonists, naltrexone, nalmefene, and nor-BNI, on operant responding for ethanol during acute withdrawal in ethanol-dependent rats. Following 1 month of intermittent ethanol vapor exposure and when tested at a time point equal to $6 \mathrm{~h}$ into withdrawal, the vapor-exposed groups displayed increased responding for ethanol compared to the air-exposed controls which is consistent with previous studies from this laboratory (Roberts et al, 1996, 2000; O'Dell et al, 2004; Walker and Koob, 2007).

Naltrexone dose-dependently reduced ethanol self-administration at a time point corresponding to $6 \mathrm{~h}$ into withdrawal (acute withdrawal) for both the ethanoldependent and -nondependent animals, without affecting water self-administration. Nalmefene also induced a dosedependent decrease in ethanol self-administration behavior in both the nondependent and ethanol-dependent animals during acute withdrawal, also without affecting water selfadministration. These results are consistent with the 
published literature which identifies that both nalmefene (June et al, 1998, 2004) and naltrexone (Stromberg et al, 1998, 2001; Coonfield et al, 2002; Shoemaker et al, 2002; Stromberg, 2004) have the ability to attenuate ethanol consummatory behaviors.

As noted above, naltrexone and nalmefene have a differential profile in binding to opioid receptors. When a direct comparison was made between naltrexone and nalmefene on opioid receptor binding affinity, it was clearly shown that while both nalmefene and naltrexone had equipotent binding affinities for the $\mu$-opioid receptor, nalmefene had a twofold increase in potency at the $\kappa$-opioid receptor compared to naltrexone (Michel et al, 1985) at low doses. The affinity of nalmefene for the $\kappa$-opioid receptor has also been observed in humans (Bart et al, 2005). In the present experiment, a dose-to-dose comparison was made possible by the fact that nalmefene and naltrexone have virtually identical molecular weights (339.4 and 341.4, respectively) and pharmacokinetic profiles (Advanced Chemistry Development, 2006). Equivalent doses (0.1 mg/ $\mathrm{kg}$ ) of nalmefene and naltrexone attenuated ethanol selfadministration similarly in nondependent animals which presumably reflects their comparable binding profiles at the $\mu$-opioid receptor. Conversely, when those same doses of nalmefene and naltrexone were tested in ethanol-dependent animals during acute withdrawal, nalmefene significantly decreased responding for ethanol, whereas naltrexone did not. It was only when the dose of naltrexone was raised that it had the ability to reduce the responding of ethanoldependent animals, reflecting that at higher concentrations there was increased binding at non- $\mu$-opioid receptors. The dissociation found between nalmefene and naltrexone at low doses suggests that some adaptation had occurred in the opioid peptide systems that only became evident when two ligands with differential affinities for the opioid receptors were used. Since the primary difference between the two compounds is their binding profile (ie $\kappa$-opioid receptor binding or not), a putative explanation for the differential effects on ethanol consumption would be that changes in the non $\mu$-opioid receptor-regulated portion of the opioid peptide system are occurring during the transition to dependence. Thus, by administering a compound that can antagonize the $\kappa$-opioid receptor in addition to antagonizing the $\mu$-opioid receptor (ie nalmefene), the result was significantly more suppression of ethanol responding.

Because the naltrexone dose-response curve was established after the nalmefene dose-response curve, it could be that the decreased efficacy of naltrexone at low doses was the result of an order effect. However, there were a number of factors that helped to mitigate such a concern. First, nalmefene challenges only occurred three times with at least 3 days between each challenge, which should protect against any drug-induced neuroadaptations. Second, the animals were allowed to reestablish ethanol self-administration that was comparable to rates observed before the nalmefene challenge before naltrexone was tested. Third, the naltrexone experiment's vehicle-treated responding was virtually identical to that observed in the nalmefene component. Lastly, if three acute tests of nalmefene did somehow affect the responsivity of the system to naltrexone, one might expect those effects to occur in both nondependent and dependent animals. However, the dissociation observed was restricted to dependent animals only, while the nondependent animal's level of responding was relatively comparable for both nalmefene and naltrexone. In summary, the three acute tests of nalmefene did not appear to alter the later response to naltrexone.

If the acute reinforcing properties of ethanol are in part mediated by the $\mu$-opioid receptor as suggested by the common effect of both nalmefene and naltrexone on nondependent ethanol self-administration, as well as the published literature (Hyytia, 1993; Krishnan-Sarin et al, 1998; Stromberg et al, 1998; Koob et al, 2003), then compensatory alterations in the dynorphin system would fit well with the opponent-process theory (Solomon and Corbit, 1974) and contemporary theories of allostasis (Koob et al, 1997; Roberts et al, 2000; Koob and Le Moal, 2001) when applied to animals in an ethanol-dependent state. Thus, if $\mu$-opioid receptor stimulation produces positive hedonic states (Amalric et al, 1987), then one putative compensatory mechanism that could occur would be an increase in the function of dynorphin and/or the $\kappa$-opioid receptors, stimulation of which produces negative hedonic states (Mucha and Herz, 1985). The dynorphin/ $\kappa$-opioid receptor system is morphologically in a spatial location that enables it to oppose the effects of $\mu$-opioid receptor agonists (Di Chiara and Imperato, 1988b) and directly inhibit motivationally relevant dopamine neurons at both the somatic and terminal regions within the mesocorticolimbic dopamine system (Di Chiara and Imperato, 1988a; Margolis et al, 2003, 2006).

To directly test the hypothesis that alterations in dynorphin systems are involved in the increased responding for ethanol in dependence, nor-BNI, a selective $\kappa$-opioid receptor antagonist was administered ICV before ethanol self-administration sessions in nondependent and ethanoldependent animals during acute withdrawal. The results showed a selective effect of nor-BNI on alcohol selfadministration in dependent animals, whereas nondependent animals were unaffected by nor-BNI treatment. Nor-BNI has been shown to have long-term effects (Jewett and Woods, 1995; Picker et al, 1996), however, in the present experiment it was of interest to see whether a dose-response curve could be established and thus, the injection regimen was conducted according to a Latin square design. Although the doses of nor-BNI were statistically different from vehicle in dependent animals, the doses did not differ from each other. These results are consistent with the hypothesized upregulation of dynorphin systems observed following chronic ethanol as suggested by decreased mRNA for $\kappa$-opioid receptors in the NAc and VTA (Rosin et al, 1999), as well as increased expression of dynorphin B in the NAc (Lindholm et al, 2000). The present data are also consistent with previous research which found that nor-BNI did not affect nondependent ethanol self-administration (Doyon et al, 2006) or consumption of ethanol within the context of the alcohol deprivation effect (Holter et al, 2000).

The effects of nor-BNI also fit well with early theories of motivation such as the Opponent-Process Theory (Solomon and Corbit, 1974), which provides an explanation for changes in the hedonic effects of drugs of abuse with chronic intake. Essentially, this theory states that an 
increase in hedonic state will be followed by a compensatory decrease in hedonic state. Furthermore, over time, the positive hedonic state is reduced while the negative affective component is enhanced to compensate for the continued perturbation of the affective system. These opponentprocess changes have been linked to allostatic mechanisms (Koob and Le Moal, 1997, 2001), which are hypothesized to reflect a new set point from which an individual would be required to continue ingesting drugs of abuse to maintain a normal emotional state that without drug is severely attenuated.

This opponent-process hypothesis for ethanol dependence is supported by the fact that intracranial selfstimulation thresholds are increased (reflecting anhedonia/dysphoria) during acute withdrawal following chronic ethanol (Schulteis et al, 1995), as well as the fact that in the present experiment, blockade of $\kappa$-opioid receptors and presumably endogenous dynorphins by nor-BNI was able to suppress selectively ethanol self-administration in dependent rats while leaving nondependent self-administration intact. Thus, nor-BNI could be modulating the anhedonia/ dysphoria that occurs during withdrawal in dependent animals.

The exact nature of the changes in dynorphin systems that occur during ethanol dependence and withdrawal remains to be established. However, in support of the hypothesis that upregulated dynorphin systems could be contributing to increased ethanol self-administration during withdrawal in dependent animals, there is considerable evidence that blockade of dynorphin systems has efficacy in animal models of depression, such as the forced swim test (Pliakas et al, 2001; Mague et al, 2003) and the learned helplessness paradigm (Newton et al, 2002; Shirayama et al, 2004). Furthermore, not only do models of depression induce changes in the immunoreactivity of dynorphin in limbic structures such as the NAc, but certain stressors do as well (Shirayama et al, 2004) and blockade of dynorphin ameliorates stress-induced enhancement of cocaine-conditioned place preferences (McLaughlin et al, 2003). Therefore, it could be that these affect- and stress-related systems are being modified during dependence and withdrawal and that the efficacy of nor-BNI is through blockade of these systems.

In summary, the present experiment identified that intermittent ethanol vapor exposure was able to induce dependent-like behavior in Wistar rats as expressed by increased ethanol intake. Nalmefene suppressed ethanol self-administration in ethanol-dependent animals when compared to naltrexone, whereas nalmefene and naltrexone affected nondependent self-administration comparably. This dissociation suggested that opioid peptide systems distinct from $\mu$-regulated functioning were undergoing neuroadaptation during the transition to dependence. In direct support of this hypothesis, blockade of endogenous dynorphins by nor-BNI was found to selectively decrease ethanol self-administration in dependent animals, with no apparent effects of nor-BNI in nondependent animals. This suggests that endogenous dynorphin/ $\kappa$-opioid receptor function is altered in ethanol dependence and withdrawal and that these alterations could be targeted to alleviate the negative emotional states associated with ethanol withdrawal and dependence.

\section{ACKNOWLEDGEMENTS}

Support for this Research was provided by National Institute on Alcohol Abuse and Alcoholism grants awarded to GFK (AA012602) and a National Research Service Award awarded to BMW (AA014723). We thank Dr. Eric Zorrilla for his statistical advice, Maury Cole, Mallinckrodt Inc., and The Pearson Center for Alcoholism and Addiction Research for their assistance with this project and Mike Arends for editorial assistance.

\section{DISCLOSURES}

Neither of the authors has any conflicts of interest related or unrelated to this manuscript.

\section{REFERENCES}

Abbott FV, Franklin KB, Libman RB (1986). A dose-ratio comparison of mu and kappa agonists in formalin and thermal pain. Life Sci 39: 2017-2024.

Agmo A, Gomez M (1991). Conditioned place preference produced by infusion of Met-enkephalin into the medial preoptic area. Brain Res 550: 343-346.

Amalric M, Cline EJ, Martinez Jr JL, Bloom FE, Koob GF (1987). Rewarding properties of beta-endorphin as measured by conditioned place preference. Psychopharmacology (Berl) 91: 14-19.

Anderson WW, Thompson T (1974). Ethanol self-administration in water satiated rats. Pharmacol Biochem Behav 2: 447-454.

Anton RF, Pettinati H, Zweben A, Kranzler HR, Johnson B, Bohn $\mathrm{MJ}$ et al (2004). A multi-site dose ranging study of nalmefene in the treatment of alcohol dependence. J Clin Psychopharmacol 24: 421-428.

Bart G, Schluger JH, Borg L, Ho A, Bidlack JM, Kreek MJ (2005). Nalmefene induced elevation in serum prolactin in normal human volunteers: partial kappa opioid agonist activity? Neuropsychopharmacology 30: 2254-2262.

Belluzzi JD, Stein L (1977). Enkephaline may mediate euphoria and drive-reduction reward. Nature 266: 556-558.

Bozarth MA (1990). Evidence for the rewarding effects of ethanol using the conditioned place preference method. Pharmacol Biochem Behav 35: 485-487.

Chen F, Lawrence AJ (2000). Effect of chronic ethanol and withdrawal on the mu-opioid receptor- and 5-hydroxytryptamine(1A) receptor-stimulated binding of [(35)S]guanosine5'-O-(3-thio)triphosphate in the fawn-hooded rat brain: a quantitative autoradiography study. J Pharmacol Exp Ther 293: 159-165.

Coonfield DL, Hill KG, Kaczmarek HJ, Ferraro III FM, Kiefer SW (2002). Low doses of naltrexone reduce palatability and consumption of ethanol in outbred rats. Alcohol 26: 43-47.

Cowen MS, Lawrence AJ (2001). Alterations in central preproenkephalin mRNA expression after chronic free-choice ethanol consumption by fawn-hooded rats. Alcohol Clin Exp Res 25: 1126-1133.

Dai X, Thavundayil J, Gianoulakis C (2005). Differences in the peripheral levels of beta-endorphin in response to alcohol and stress as a function of alcohol dependence and family history of alcoholism. Alcohol Clin Exp Res 29: 1965-1975.

Di Chiara G, Imperato A (1988a). Drugs abused by humans preferentially increase synaptic dopamine concentrations in the mesolimbic system of freely moving rats. Proc Natl Acad Sci USA 85: 5274-5278.

Di Chiara G, Imperato A (1988b). Opposite effects of mu and kappa opiate agonists on dopamine release in the nucleus 
accumbens and in the dorsal caudate of freely moving rats. J Pharmacol Exp Ther 244: 1067-1080.

Doyon WM, Howard EC, Shippenberg TS, Gonzales RA (2006). Kappa-opioid receptor modulation of accumbal dopamine concentration during operant ethanol self-administration. Neuropharmacology 51: 487-496.

Eckardt MJ, File SE, Gessa GL, Grant KA, Guerri C, Hoffman PL et al (1998). Effects of moderate alcohol consumption on the central nervous system. Alcohol Clin Exp Res 22: 998-1040.

Gianoulakis C, Krishnan B, Thavundayil J (1996). Enhanced sensitivity of pituitary beta-endorphin to ethanol in subjects at high risk of alcoholism. Arch Gen Psychiatry 53: 250-257.

Goeders NE, Lane JD, Smith JE (1984). Self-administration of methionine enkephalin into the nucleus accumbens. Pharmacol Biochem Behav 20: 451-455.

Gonzales RA, Weiss F (1998). Suppression of ethanol-reinforced behavior by naltrexone is associated with attenuation of the ethanol-induced increase in dialysate dopamine levels in the nucleus accumbens. J Neurosci 18: 10663-10671.

Holter SM, Henniger MS, Lipkowski AW, Spanagel R (2000). Kappa-opioid receptors and relapse-like drinking in long-term ethanol-experienced rats. Psychopharmacology (Berl) 153: 93-102.

Hubbell CL, Abelson ML, Burkhardt CA, Herlands SE, Reid LD (1988). Constant infusions of morphine and intakes of sweetened ethanol solution among rats. Alcohol 5: 409-415.

Hyytia P (1993). Involvement of mu-opioid receptors in alcohol drinking by alcohol-preferring AA rats. Pharmacol Biochem Behav 45: 697-701.

Jewett DC, Woods JH (1995). Nor-binaltorphimine: an ultra-long acting kappa-opioid antagonist in pigeons. Behav Pharmacol 6: 815-820.

June HL, Cummings R, Eiler WJ, Foster KL, McKay PF, Seyoum R et al (2004). Central opioid receptors differentially regulate the nalmefene-induced suppression of ethanol- and saccharinreinforced behaviors in alcohol-preferring $(\mathrm{P})$ rats. Neuropsychopharmacology 29: 285-299.

June HL, Grey C, Warren-Reese C, Durr LF, Ricks-Cord A, Johnson A et al (1998). The opioid receptor antagonist nalmefene reduces responding maintained by ethanol presentation: preclinical studies in ethanol-preferring and outbred Wistar rats. Alcohol Clin Exp Res 22: 2174-2185.

Koob GF, Caine SB, Parsons L, Markou A, Weiss F (1997). Opponent process model and psychostimulant addiction. Pharmacol Biochem Behav 57: 513-521.

Koob GF, Le Moal M (1997). Drug abuse: hedonic homeostatic dysregulation. Science 278: 52-58.

Koob GF, Le Moal M (2001). Drug addiction, dysregulation of reward, and allostasis. Neuropsychopharmacology 24: 97-129.

Koob GF, Roberts AJ, Kieffer BL, Heyser CJ, Katner SN, Ciccocioppo $\mathrm{R}$ et al (2003). Animal models of motivation for drinking in rodents with a focus on opioid receptor neuropharmacology. Recent Dev Alcohol 16: 263-281.

Krishnan-Sarin S, Wand GS, Li XW, Portoghese PS, Froehlich JC (1998). Effect of mu opioid receptor blockade on alcohol intake in rats bred for high alcohol drinking. Pharmacol Biochem Behav 59: 627-635.

Lindholm S, Ploj K, Franck J, Nylander I (2000). Repeated ethanol administration induces short- and long-term changes in enkephalin and dynorphin tissue concentrations in rat brain. Alcohol 22: 165-171.

Mague SD, Pliakas AM, Todtenkopf MS, Tomasiewicz HC, Zhang Y, Stevens Jr WC et al (2003). Antidepressant-like effects of kappa-opioid receptor antagonists in the forced swim test in rats. J Pharmacol Exp Ther 305: 323-330.

Marglin SH, MacKechnie DK, Mattie ME, Hui YH, Reid LD (1988). Ethanol with small doses of morphine establishes a conditioned place preference. Alcohol 5: 309-313.

Margolis EB, Hjelmstad GO, Bonci A, Fields HL (2003). Kappaopioid agonists directly inhibit midbrain dopaminergic neurons. J Neurosci 23: 9981-9986.
Margolis EB, Lock H, Chefer VI, Shippenberg TS, Hjelmstad GO, Fields HL (2006). Kappa opioids selectively control dopaminergic neurons projecting to the prefrontal cortex. Proc Natl Acad Sci USA 103: 2938-2942.

Marinelli PW, Bai L, Quirion R, Gianoulakis C (2005). A microdialysis profile of Met-enkephalin release in the rat nucleus accumbens following alcohol administration. Alcohol Clin Exp Res 29: 1821-1828.

Marinelli PW, Lam M, Bai L, Quirion R, Gianoulakis C (2006). A microdialysis profile of dynorphin $\mathrm{A}(1-8)$ release in the rat nucleus accumbens following alcohol administration. Alcohol Clin Exp Res 30: 982-990.

Marinelli PW, Quirion R, Gianoulakis C (2003). A microdialysis profile of beta-endorphin and catecholamines in the rat nucleus accumbens following alcohol administration. Psychopharmacology (Berl) 169: 60-67.

Marinelli PW, Quirion R, Gianoulakis C (2004). An in vivo profile of beta-endorphin release in the arcuate nucleus and nucleus accumbens following exposure to stress or alcohol. Neuroscience 127: 777-784.

Mason BJ, Ritvo EC, Morgan RO, Salvato FR, Goldberg G, Welch B et al (1994). A double-blind, placebo-controlled pilot study to evaluate the efficacy and safety of oral nalmefene $\mathrm{HCl}$ for alcohol dependence. Alcohol Clin Exp Res 18: 1162-1167.

McLaughlin JP, Marton-Popovici M, Chavkin C (2003). Kappa opioid receptor antagonism and prodynorphin gene disruption block stress-induced behavioral responses. J Neurosci 23: 5674-5683.

Michel ME, Bolger G, Weissman BA (1985). Binding of a new opiate antagonist, nalmefene, to rat brain membranes. Methods Find Exp Clin Pharmacol 7: 175-177.

Millan MJ (1989). Kappa-opioid receptor-mediated antinociception in the rat. I. Comparative actions of mu- and kappaopioids against noxious thermal, pressure and electrical stimuli. J Pharmacol Exp Ther 251: 334-341.

Millan MJ, Czlonkowski A, Lipkowski A, Herz A (1989). Kappaopioid receptor-mediated antinociception in the rat. II. Supraspinal in addition to spinal sites of action. J Pharmacol Exp Ther 251: 342-350.

Mucha RF, Herz A (1985). Motivational properties of kappa and $\mathrm{mu}$ opioid receptor agonists studied with place and taste preference conditioning. Psychopharmacology (Berl) 86: 274-280.

Newton SS, Thome J, Wallace TL, Shirayama Y, Schlesinger L, Sakai N et al (2002). Inhibition of cAMP response elementbinding protein or dynorphin in the nucleus accumbens produces an antidepressant-like effect. J Neurosci 22: 1088310890.

O'Dell LE, Roberts AJ, Smith RT, Koob GF (2004). Enhanced alcohol self-administration after intermittent versus continuous alcohol vapor exposure. Alcohol Clin Exp Res 28: $1676-1682$

Paxinos G, Watson C (2005). The Rat Brain in Stereotaxic Coordinates. Elsevier, Academic Press: San Diego.

Picker MJ, Mathewson C, Allen RM (1996). Opioids and rate of positively reinforced behavior: III. Antagonism by the longlasting kappa antagonist norbinaltorphimine. Behav Pharmacol 7: 495-504.

Pliakas AM, Carlson RR, Neve RL, Konradi C, Nestler EJ, Carlezon Jr WA (2001). Altered responsiveness to cocaine and increased immobility in the forced swim test associated with elevated cAMP response element-binding protein expression in nucleus accumbens. J Neurosci 21: 7397-7403.

Przewlocka B, Turchan J, Lason W, Przewlocki R (1997). Ethanol withdrawal enhances the prodynorphin system activity in the rat nucleus accumbens. Neurosci Lett 238: $13-16$. 
Reid LD (1996). Endogenous opioids and alcohol dependence: opioid alkaloids and the propensity to drink alcoholic beverages. Alcohol 13: 5-11.

Roberts AJ, Cole M, Koob GF (1996). Intra-amygdala muscimol decreases operant ethanol self-administration in dependent rats. Alcohol Clin Exp Res 20: 1289-1298.

Roberts AJ, Heyser CJ, Cole M, Griffin P, Koob GF (2000). Excessive ethanol drinking following a history of dependence: animal model of allostasis. Neuropsychopharmacology 22: 581-594.

Rogers J, Wiener SG, Bloom FE (1979). Long-term ethanol administration methods for rats: advantages of inhalation over intubation or liquid diets. Behav Neural Biol 27: 466-486.

Rosin A, Lindholm S, Franck J, Georgieva J (1999). Downregulation of kappa opioid receptor mRNA levels by chronic ethanol and repetitive cocaine in rat ventral tegmentum and nucleus accumbens. Neurosci Lett 275: 1-4.

Rubin DB (1987). Multiple Imputation for Nonresponse in Surveys. J. Wiley \& Sons: New York.

Rubin DB (1996). Multiple imputation after 18+ years. Journal of the American Statistical Association 91: 473-489.

Samson HH (1986). Initiation of ethanol reinforcement using a sucrose-substitution procedure in food- and water-sated rats. Alcohol Clin Exp Res 10: 436-442.

Schafer JL (1999). Multiple imputation: a primer. Stat Methods Med Res 8: 3-15.

Schafer JL, Graham JW (2002). Missing data: our view of the state of the art. Psychol Methods 7: 147-177.

Schulteis G, Markou A, Cole M, Koob GF (1995). Decreased brain reward produced by ethanol withdrawal. Proc Natl Acad Sci USA 92: 5880-5884.

Shirayama Y, Ishida H, Iwata M, Hazama GI, Kawahara R, Duman RS (2004). Stress increases dynorphin immunoreactivity in limbic brain regions and dynorphin antagonism produces antidepressant-like effects. J Neurochem 90: 1258-1268.

Shoemaker WJ, Vavrousek-Jakuba E, Arons CD, Kwok FC (2002). The acquisition and maintenance of voluntary ethanol drinking in the rat: effects of dopaminergic lesions and naloxone. Behav Brain Res 137: 139-148.

Smith SG, Davis WM (1974). Intravenous alcohol self-administration in the rat. Pharmacol Res Commun 6: 379-402.

Solomon RL, Corbit JD (1974). An opponent-process theory of motivation. I. Temporal dynamics of affect. Psychol Rev 81: 119-145.

Stromberg MF (2004). The effect of baclofen alone and in combination with naltrexone on ethanol consumption in the rat. Pharmacol Biochem Behav 78: 743-750.

Stromberg MF, Casale M, Volpicelli L, Volpicelli JR, O’Brien CP (1998). A comparison of the effects of the opioid antagonists naltrexone, naltrindole, and beta-funaltrexamine on ethanol consumption in the rat. Alcohol 15: 281-289.

Stromberg MF, Mackler SA, Volpicelli JR, O'Brien CP (2001). Effect of acamprosate and naltrexone, alone or in combination, on ethanol consumption. Alcohol 23: 109-116.

Turchan J, Przewlocka B, Toth G, Lason W, Borsodi A, Przewlocki $\mathrm{R}$ (1999). The effect of repeated administration of morphine, cocaine and ethanol on mu and delta opioid receptor density in the nucleus accumbens and striatum of the rat. Neuroscience 91 : 971-977.

Volpicelli JR, Alterman AI, Hayashida M, O’Brien CP (1992). Naltrexone in the treatment of alcohol dependence. Arch Gen Psychiatry 49: 876-880.

Walker BM, Ettenberg A (2007). Intracerebroventricular ethanolinduced conditioned place preferences are prevented by fluphenazine infusions into the nucleus accumbens of rats. Behav Neurosci 21: 401-410.

Walker BM, Koob GF (2007). The $\mathrm{GABA}_{\mathrm{B}}$ receptor agonist baclofen attenuates operant responding for ethanol in ethanol-dependant rats. Alcohol Clin Exp Res 31: 11-18.

Walker EA, Makhay MM, House JD, Young AM (1994). In vivo apparent pA2 analysis for naltrexone antagonism of discriminative stimulus and analgesic effects of opiate agonists in rats. J Pharmacol Exp Ther 271: 959-968. 